\title{
Metodología y estado actual del patrimonio paleontológico en el Inventario Español de Lugares de Interés Geológico
}

\author{
Juana VEGAS ${ }^{1^{*}}$, Graciela DELVENE2, Silvia MENÉNDEZ2, Ana CABRERA ${ }^{1}$, Ángel \\ GARCÍA-CORTÉS', Enrique DÍAZ-MARTÍNEZ1, Luis CARCAVILLA \& Isabel RÁBANO ${ }^{2}$
}

\begin{abstract}
${ }^{1}$ Área de Patrimonio Geológico y Minero. Instituto Geológico y Minero de España. Ríos Rosas 23. 28003 Madrid; j.vegas@igme.es, a.cabrera@igme.es, garcia.cortes@igme.es, e.diaz@igme.es, 1.carcavilla@igme.es

${ }^{2}$ Museo Geominero. Instituto Geológico y Minero de España. Ríos Rosas 23.28003 Madrid; g.delvene@igme.es, s.menendez@igme.es, i.rabano@igme.es

* Corresponding author
\end{abstract}

Vegas, J., Delvene, G., Menéndez, S., Cabrera, A., García-Cortés, Á., Díaz-Martínez, E., Carcavilla, L. \& Rábano, I. 2019. Metodología y estado actual del patrimonio paleontológico en el Inventario Español de Lugares de Interés Geológico. [Methodology and state-of-the-art of the palaeontological heritage included in the Spanish Inventory of Sites of Geological Interest]. Spanish Journal of Palaeontology, 34 (1), 17-34.

Manuscript received 17 February 2019

Manuscript accepted 22 May 2019 https://doi 10.7203/sjp.34.1.15221

(C) Sociedad Española de Paleontología ISSN 2255-0550

\section{RESUMEN}

El Inventario Español de Lugares de Interés Geológico (en adelante IELIG) es un inventario de patrimonio geológico sistemático de reconocimiento avanzado, que está diseñado metodológicamente para cubrir todo el territorio español e identificar los Lugares de Interés Geológico (en adelante LIG) de relevancia nacional de cada uno de los dominios geológicos del país. Este inventario está recogido expresamente en la Ley 42/2007 de patrimonio natural y la biodiversidad y el Real Decreto 556/2011, 20 de abril, para el desarrollo del Inventario Español del Patrimonio Natural y la Biodiversidad. Por este motivo, el IELIG tiene que ser representativo de la geodiversidad española y comprende LIG de todas las disciplinas de la Geología, incluyendo aquellos cuyo interés principal es de tipo paleontológico. Se han cuantificado los diferentes tipos de LIG de acuerdo a sus principales intereses taxonómico y geográfico. Algunos de ellos han sido seleccionados para relacionarlos con el patrimonio mueble y analizar los diversos factores que les han afectado a lo largo del tiempo.

Palabras clave: Inventario, patrimonio geológico, patrimonio paleontológico, legislación, España.

\begin{abstract}
The Spanish Inventory of Sites of Geological Interest (IELIG is the acronym in Spanish) is a systematic geoheritage inventory of advanced recognition, which is methodologically designed to cover the entire Spanish territory and to identify the Sites of Geological Interest (geosites or LIG: acronym in Spanish) of national relevance of each of the main geological domains of the country. This inventory is expressly included in Law 42/2007 on natural heritage and biodiversity and Royal Decree 556/2011, for the development of the Spanish Inventory of Natural Heritage and Biodiversity. For this reason, the IELIG has to be representative of the Spanish geodiversity and includes geosites of all the disciplines of Geology, including those whose main interest is of palaeontological type. The different types of geosites of palaeontological interest included in the IELIG have been analyzed according to their main taxonomic interests and geographical situation. Some of the more relevant palaeontological geosites have been selected to relate them to movable geoheritage located in museums and collections in order to analyze the various factors that have affected them over time.
\end{abstract}

Keywords: Inventory, geoheritage, palaeontological heritage, legislation, Spain. 


\section{INTRODUCCIÓN}

\subsection{Patrimonio geológico de tipo paleontológico}

El patrimonio geológico de tipo paleontológico (mueble e inmueble) es el conjunto de fósiles, tanto corporales como moldes, impresiones o icnofósiles que se han conservado en el registro geológico, a los que se les asigna un valor científico, didáctico y/o cultural. Los fósiles son elementos naturales puesto que se forman por procesos naturales (presencia de seres vivos, sus restos y sus huellas, sedimentación y conservación mediante procesos similares a los que acontecen en la diagénesis) y se mantienen dentro de la geosfera (Fernández López, 1998). El patrimonio se puede definir, de forma genérica, como los elementos o bienes a los que los seres humanos atribuimos o asignamos un valor, generalmente por ofrecer algún tipo de beneficio o interés, real o potencial. Por lo tanto, el patrimonio tangible siempre consta de una parte objetiva e inalterable que es el elemento o elementos que lo integran, y una parte subjetiva, la cual puede cambiar, y que es el valor que damos a estos elementos (DíazMartínez, 2011). Al mismo tiempo, el valor o interés es un parámetro imprescindible e intrínseco al concepto de patrimonio, algo que necesariamente tiene que existir para que un elemento pueda ser considerado como patrimonio (Díaz-Martínez \& Fernández-Martínez, 2015).

El valor es, en todo caso, un parámetro que debe ser establecido por los especialistas competentes en cada disciplina, que en el caso que nos ocupa es la paleontología. Son estos especialistas quienes deberán determinar qué fósiles y qué yacimientos paleontológicos tienen valor (científico, didáctico y/o cultural) y, por tanto, formarán parte del patrimonio geológico de tipo paleontológico. El valor científico de los fósiles y yacimientos paleontológicos viene dado por muchos factores, algunos de ellos son: taxonómicos (género y especie); definir localidades-tipo al ser los lugares donde se definió una determinada especie fósil; bioestratigráficos por ser marcadores temporales y estar relacionados con la elaboración de la escala cronoestratigráfica; tafonómicos debido a los procesos y condiciones de la fosilización; ser indicadores de la paleodiversidad; y paleoecológicos porque sirven para estudiar las relaciones entre los organismos, el clima y su ambiente.

Su inclusión dentro de los inventarios de patrimonio geológico temáticos (p.e. Alcalá \& Morales, 1991; Meléndez \& Soria, 1994, 1999; Meléndez \& Soria Llop, 2000, 2002; Morales 1996; Castillo et al., 1999; Henriques \& Pena dos Reis, 2015) o sistemáticos (p.e. Mendía et al., 2013; García-Cortés et al., 2018) se realiza aplicando los criterios de valoración propios de la metodología del patrimonio geológico. Por tanto, en rigor, el patrimonio paleontológico, de acuerdo con su carácter y origen natural y aplicando la metodología necesaria para ser establecido, debe considerarse patrimonio natural y no patrimonio cultural (Díaz-Martínez, 2011; Díaz-Martínez et al., 2013, 2016).

Con frecuencia hay publicaciones científicas e inventarios de patrimonio geológico que versan exclusivamente sobre una disciplina y que se denominan temáticos (p.e. patrimonio paleontológico, patrimonio geomorfológico, patrimonio mineralógico, etc.). No es de extrañar, puesto que la geología es una ciencia que cubre un gran abanico de disciplinas y materias a tratar (p.e. ver códigos UNESCO de clasificación de las ciencias de la Tierra). Las ciencias de la Tierra han llegado a tal grado de especialización que difícilmente una misma persona puede dominar varios campos de investigación. En el caso del patrimonio geológico, esto se traduce en que a menudo se realicen estudios parciales enfocados desde sus disciplinas, como ocurre con el patrimonio paleontológico (p.e. Morales Romero et al., 1999; Gómez \& Morales, 2000; Romero, 2005). Los estudios e inventarios temáticos indudablemente tienen su interés, pero no debe perderse de vista que son sólo una parte del patrimonio geológico en su conjunto y, por lo tanto, en su estudio deberían adoptar la metodología general de investigación, adaptándola, eso sí, a las características de la disciplina a investigar.

Una particularidad del patrimonio de tipo paleontológico viene dada porque muchos de sus componentes no son lugares, sino ejemplares singulares. Las técnicas de investigación paleontológica exigen, en la mayoría de los casos, extraer el fósil y estudiarlo en un laboratorio, lo cual supone una modificación irreversible. Es lo que se denomina patrimonio geológico mueble, es decir, extraído de su lugar original y que pasa a custodiarse o conservarse ex situ como parte de una colección de fósiles museística o científica. Por su parte, el patrimonio paleontológico inmueble estará formado por yacimientos y secciones con un interés especial desde el punto de vista de su registro fósil, ya sea por su especial conservación, singularidad, abundancia, diversidad o importancia científica (edad del yacimiento, origen histórico, material o localidad tipo, etc.). Es evidente que la gestión de un fósil perteneciente a la colección custodiada en un museo no se parece en nada a la de un yacimiento situado en un contexto natural. La problemática de su conservación es totalmente diferente, las posibilidades de investigación y divulgación también, y las normativas legales que rigen su gestión son, así mismo, distintas. Por eso es tan importante la distinción entre el patrimonio geológico (en general, incluyendo el paleontológico) mueble y el inmueble.

El Inventario Español de Lugares de Interés Geológico (IELIG) se desarrolló a raíz de la aprobación de la Ley 42/2007 de patrimonio natural y biodiversidad en España. Es un inventario de patrimonio geológico que cubre la escala nacional y que se denomina "de reconocimiento avanzado", en el cual los LIG se seleccionan recurriendo a encuestas por expertos conocedores de las diferentes 
disciplinas de la Geología del dominio geológico inventariado siguiendo la metodología Delphi (Carcavilla Urquí et al., 2007; García-Cortés et al., 2018). No sólo se identifica la ubicación y relevancia de los LIG; además con esta metodología también se aportan las bases para adoptar medidas adecuadas para su conservación y aprovechamiento, es decir para la gestión de los LIG, individualmente o como conjunto. En este trabajo, se detalla cuál es el estado actual del IELIG y se analiza cómo se aborda la selección de los LIG, en concreto los de interés principal de tipo paleontológico, y cuál es la metodología seguida en el IELIG para su valoración.

\subsection{Legislación asociada al patrimonio de tipo paleontológico}

En nuestro país, el patrimonio paleontológico queda recogido en la legislación estatal en dos leyes de muy diferente naturaleza. En orden cronológico, los fósiles se mencionaron expresamente por primera vez en la Ley 16/1985 de Patrimonio Histórico Español, donde textualmente se dice que "...forman parte, asimismo, de este Patrimonio [histórico] los elementos geológicos y paleontológicos relacionados con la historia del hombre y sus orígenes y antecedentes". A partir de esta ley se han redactado las posteriores leyes autonómicas y decretos sobre patrimonio histórico y cultural, que en algunos casos interpretan que deben contemplar un registro fósil que incluya todos los elementos, aun siendo anteriores al origen de los seres humanos y su evolución en el planeta (Díaz-Martínez et al., 2016; Delvene et al., 2016, 2018). Transcurridos 22 años, cuando la mayoría de las comunidades autónomas (CCAA) tenían legislaciones sobre patrimonio cultural y algunas gestionaban el patrimonio paleontológico desde las consejerías de cultura, se promulgó la Ley 42/2007 y su modificación en la Ley 33/2015 de Patrimonio Natural y la Biodiversidad, que consideran expresamente a los fósiles como elementos geológicos que forman parte de la naturaleza. En esta Ley, el patrimonio geológico está definido como el "conjunto de recursos naturales geológicos de valor científico, cultural y/o educativo, ya sean formaciones y estructuras geológicas, formas del terreno, minerales, rocas, meteoritos, fósiles, suelos y otras manifestaciones geológicas que permiten conocer, estudiar e interpretar: a) el origen y evolución de la Tierra, b) los procesos que la han modelado, c) los climas y paisajes del pasado y presente y d) el origen y evolución de la vida" [la negrita es nuestra]. La consecuencia principal de esta dualidad legislativa es la variada manera de afrontar su reconocimiento, su gestión y su protección en el ámbito de las consejerías de medioambiente y cultura en las CCAA. Se ha discutido esta situación de forma más amplia en Díaz-Martínez et al. (2013, 2016), Delvene et al. (2016, 2018) y Vegas et al. (2017).

\section{EL INVENTARIO ESPAÑOL DE LUGARES DE INTERÉS GEOLÓGICO (IELIG)}

\subsection{Antecedentes y marco normativo del IELIG}

A finales de la década de los setenta del siglo XX se impulsó el comienzo de una labor de sistematización del conocimiento del patrimonio geológico en España mediante el proyecto denominado "Inventario Nacional de Puntos de Interés Geológico" (INPIG) por profesionales del Instituto Geológico y Minero de España (IGME). Dentro de este proyecto se desarrollaron varios trabajos metodológicos y de inventario (Elízaga et al., 1980, 1994; Elízaga, 1988), con inventarios concretos de Galicia, Asturias, Cordillera Cantábrica, Comunidad Valenciana, Teruel, Murcia, Albacete y Menorca (Duque et al., 1983; Águeda et al., 1985). El porcentaje estudiado en este periodo fue aproximadamente de un $16 \%$ de la superficie del país.

Posteriormente, el Inventario Nacional de PIG se vio interrumpido por motivos presupuestarios, por lo que la catalogación de lugares de interés geológico se limitó a la incorporación, a partir del año 1989, del inventario de puntos de interés geológico como un apartado dentro de la memoria que acompaña a la cartografía del Mapa Geológico Nacional (serie MAGNA) a escala 1:50.000. Durante esta etapa, se realizaron inventarios de PIG en algunas Comunidades Autónomas como el País Vasco (Tamés et al., 1991) y Murcia (Arana et al., 1999).

A comienzos del siglo XXI, se inició el desarrollo del "Inventario Español de Lugares de Interés Geológico" (IELIG), a raíz de la aprobación de la citada Ley 42/2007 de patrimonio natural y biodiversidad en España y que, en buena parte, es heredero del pionero INPIG (IGME). La metodología del IELIG (ver última actualización en García-Cortés et al., 2018) se fundamenta en una profunda revisión de las experiencias, tanto nacionales como internacionales, sobre los inventarios del patrimonio geológico, así como de sus bases conceptuales y la nueva normativa en vigor. Tras casi 40 años de experiencia en inventarios de patrimonio geológico, los tradicionales planteamientos del INPIG requerían una profunda revisión metodológica, con un triple objetivo: a) adaptarlo al actual desarrollo de las ciencias geológicas; b) responder a las obligaciones del IGME en la legislación y las políticas de conservación del patrimonio geológico y la geodiversidad en España; y, c) hacerlo más comprensible y aprovechable para las administraciones responsables de la conservación y gestión del patrimonio geológico, entre otras, las competentes en Medio Natural, Patrimonio Cultural o en desarrollo rural y turístico.

Con respecto al primer objetivo, para la actualización científica se tomaron tres iniciativas: 
1) La primera, priorizar las actuaciones de inventario en dominios geológicos concretos, frente a los anteriores proyectos enmarcados en límites administrativos.

2) La segunda, proceder a una revisión y actualización de las fichas soporte de datos, excesivamente centradas en los aspectos descriptivos y con escaso contenido interpretativo y justificativo de las razones objetivas que motivaban la selección del LIG. Crear una moderna base de datos en SQL-server donde almacenar la información que está asociada a un visor cartográfico en soporte web de acceso público.

3) Finalmente, llevar a cabo una revisión de los LIG seleccionados en las etapas iniciales del inventario, comprobar la vigencia de las selecciones realizadas en su día y detectar posibles lagunas a la luz de las recientes aportaciones de los trabajos de investigación realizados con posterioridad en el ámbito considerado.

Con respecto al segundo objetivo, el IELIG se compatibiliza con la legislación y las políticas de conservación del patrimonio geológico y la geodiversidad que surgieron a partir de 2007; como fueron la Ley 42/2007 del Patrimonio Natural y de la Biodiversidad, la 5/2007 de la Red de Parques Nacionales o la 45/2007 de Desarrollo Sostenible del Medio Rural. Todas ellas fueron novedosas, por ser la primera vez que las leyes de ámbito estatal, dictadas para la conservación de la naturaleza en nuestro país, incluían expresamente al patrimonio geológico y la geodiversidad.

La Ley 42/2007, y su modificación en la Ley 33/2015, contempla, en su artículo 9, la realización por el entonces Ministerio de Medio Ambiente, en colaboración con las CCAA y las instituciones científicas, de un inventario de lugares de interés geológico. Pero lo más novedoso de esta legislación es la promulgación de dos reales decretos asociados (Fig. 1):

1) Real Decreto 556/2011, 20 de abril, para el desarrollo del Inventario Español del Patrimonio Natural y la Biodiversidad. Aquí se indica que el principal objetivo de este Inventario es disponer de una información objetiva, fiable y comparable a nivel estatal, a partir de la cual se podrán: a) Elaborar políticas de eonservación, gestión y uso sostenible. Difundir a la sociedad los valores del Patrimonio Natural y de la Biodiversidad; y, b) atender los requerimientos de información de los compromisos internacionales.

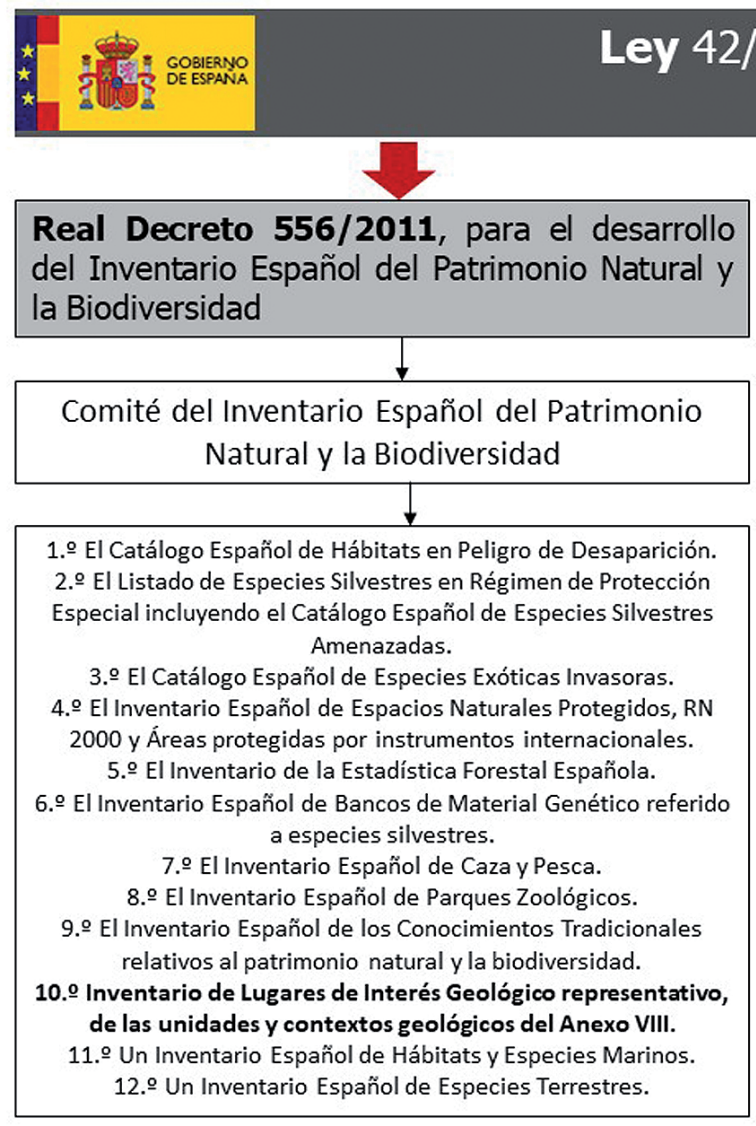

y biodiversidad

Real Decreto 556/2011, para el desarrollo del Inventario Español del Patrimonio Natural y la Biodiversidad

Comité del Inventario Español del Patrimonio Natural y la Biodiversidad

1. El Catálogo Español de Hábitats en Peligro de Desaparición. 2. El Listado de Especies Silvestres en Régimen de Protección Amenazadas.

3. El Catálogo Español de Especies Exóticas Invasoras. - El Inventario Español de Espacios Naturales Protegidos, RN y Áreas protegidas por instrumentos internacionales.

5 . El Inventario de la Estadística Forestal Española. a especies silvestres. 7.o El Inventario Español de Parques Zoológicos. El Inventario Español de los Conocimientos Tradicionales

de las unidades y contextos geológicos del Anexo VIII.

12. Un Inventario Español de Especies Terrestres.

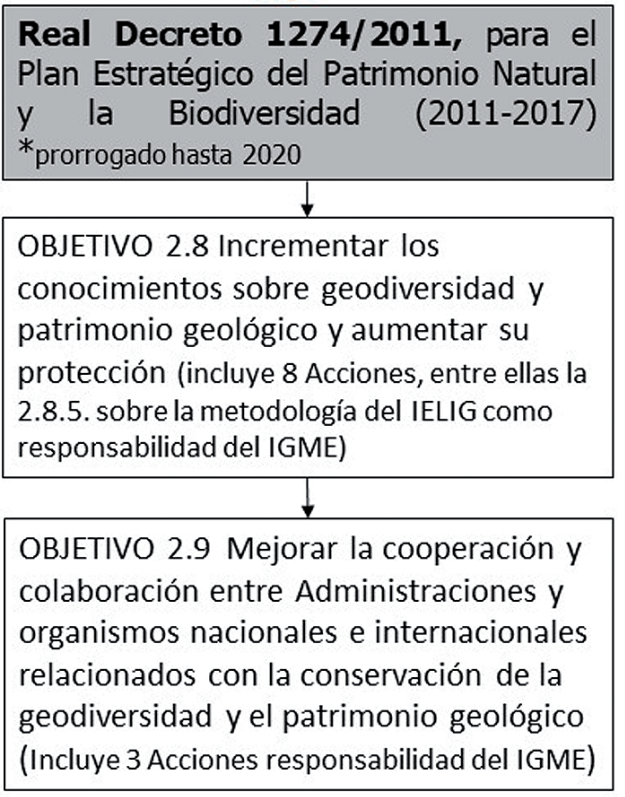

Figura 1. Estructura normativa de ámbito estatal de la que depende el IELIG (Inventario Español de Lugares de Interés Geológico) en el RD 556/2011 para el desarrollo del Inventario Español del Patrimonio Natural y la Biodiversidad, y su metodología según RD 1274/2011 para el Plan Estratégico del Patrimonio Natural y la Biodiversidad en la Acción 2.8.5. 
Para alcanzar estos objetivos se han establecido tres niveles de aproximación: los Componentes del Inventario para conocer, un Sistema de indicadores para evaluar, y un Informe Anual para difundir.

En su apartado 5.d, este RD 556/2011 incluye el INVENTARIO ESPAÑOL DE LUGARES DE INTERÉS GEOLÓGICO (que es uno de los componentes del Inventario del Patrimonio Natural como se indica en el Anexo III de este RD) con indicaciones sobre varios aspectos: a) Contenido: lugares de interés, por su carácter único o representativo, para el estudio e interpretación del origen y evolución de los grandes dominios geológicos españoles, incluyendo los procesos que los han modelado, los climas del pasado y su evolución paleobiológica. Estos grandes dominios engloban las formaciones y contextos geológicos del anexo VIII de la Ley 42/2007. b) Estructura del inventario: información cartográfica con geometría de polígonos y base de datos alfanumérica asociada. c) Periodicidad de actualización: decenal. d) Marco jurídico: Ley 42/2007, de 13 de diciembre, del Patrimonio Natural y de la Biodiversidad, artículo 9.2. Todos los datos del IELIG se albergan en un Sistema Integrado de Información que permite el análisis, integración y difusión de la información que depende del actual Ministerio para la Transición Ecológica (Banco de Datos de la Naturaleza, https://www.miteco.gob.es/es/biodiversidad/servicios/ banco-datos-naturaleza/).

En cumplimiento de este RD 556/2011, se creó el Comité del Inventario Español del Patrimonio Natural y de la Biodiversidad (Dirección General de Calidad y Evaluación Ambiental y Medio Natural), en el que hay un representante por parte del IGME, quien también tiene la coordinación del Grupo de Trabajo de Geodiversidad y es miembro del Grupo de Trabajo de Espacios Protegidos (Medio Ambiente).

2) Real Decreto 1274/2011, de 16 de septiembre, por el que se aprueba el Plan Estratégico del patrimonio natural y la biodiversidad para el periodo 2011-2017. Este RD es el elemento fundamental para el desarrollo de la Ley $42 / 2007$ de patrimonio natural y biodiversidad. Se trata de un instrumento legislativo novedoso en la legislación española, pues en él se establecen las metas, objetivos y acciones para promover la conservación, el uso sostenible y la restauración del patrimonio natural y la biodiversidad. Todo ello para el periodo 2011-2017, aunque actualmente se ha ampliado hasta 2020.

En este RD 1274/2011 se encomienda al IGME, entre otros objetivos, cumplir con la acción 2.8.5. "Concluir una metodología homogénea para el estudio e inventario del patrimonio geológico en España" y 2.8.6. "Finalizar el Inventario Español de Lugares de Interés Geológico", este último con la colaboración de la Dirección general de Calidad y Evaluación Ambiental y del Medio Natural (MAPAMA, actual MINECO) y las Comunidades Autónomas. En este contexto normativo, la metodología propuesta para el IELIG por el IGME se sometió a la consulta de más de una treintena de especialistas en Ciencias de la Tierra, de diferentes universidades y centros de investigación.

El tercer objetivo indicado es facilitar el aprovechamiento práctico del inventario español por parte de todos los potenciales usuarios. En este punto es muy importante destacar que los LIG inventariados sean valorados con una escala que permita su comparación y, sobre todo, que esta valoración se realice considerando por separado los valores científicos, didácticos y turísticos, sin posibilidad de compensación o ponderación entre ellos. Con esta manera de proceder, que también ha sido novedosa en España, se persiguen dos fines: a) Orientar a las personas no expertas en patrimonio geológico sobre el valor relativo de un lugar respecto a los demás que forman parte del inventario en la región considerada, permitiendo de ese modo priorizar ulteriores actuaciones de uso o de conservación. b) Disponer de conjuntos distinguibles de LIG con valor científico, didáctico o turístico y poder ordenarlos de mayor a menor por su grado de interés mediante su correspondiente valoración.

\subsection{Metodología del IELIG y situación actual}

El IELIG pretende cubrir toda la geografía española y, por tanto, tiene una escala supra-regional. Este inventario no se ha abordado de manera global y simultánea en todo el territorio nacional, sino que se ha realizado en sucesivos proyectos de tal forma que cada uno de ellos abarca el inventario de los diferentes dominios geológicos en los que se ha dividido el territorio (definidos en el Plan GEODE de cartografía geológica digital continua del IGME), con el objetivo de que el IELIG sea representativo de la evolución geológica de estos dominios y los procesos geológicos que han tenido lugar en los mismos.

Por tanto, en la metodología del IELIG no se contempla abordar los proyectos de inventario siguiendo límites administrativos (CCAA o provincias) sino límites geológicos. No obstante, dadas las competencias de las CCAA en materia de medio natural, se reconocen como inventarios oficiales, que por tanto forman parte del IELIG, los inventarios autonómicos realizados y aprobados por los organismos competentes que han asumido su realización (en la actualidad Cataluña, Andalucía, País Vasco y Aragón). Para la armonización de estos inventarios, se ha elaborado y aprobado, en el Comité del Inventario Español del Patrimonio Natural y de la Biodiversidad (en el que están representadas la Administración General del Estado y las CCAA), un perfil común de metadatos (MAGRAMA, 2013) y un modelo de datos mínimo (MAPAMA, 2015) para los inventarios de lugares de interés geológico. Por otro lado, para facilitar la gestión del patrimonio geológico a las administraciones competentes, es necesario 
suministrar, junto con el inventario, la cartografía de los LIG inventariados mediante polígonos, con la delimitación geográfica precisa (y no como se hacía anteriormente, cuando únicamente se indicaban con las coordenadas de un punto señalado en la cartografía 1:25.000).

La metodología del IELIG se describe en extenso en García-Cortés et al. (2018), una publicación de libre descarga desde el enlace http://www.igme.es/patrimonio. El proceso de inventario comprende dos fases: una primera de identificación y selección de LIG por parte de especialistas en todas las disciplinas siguiendo el método Delphi, y una segunda de documentación, valoración y cartografía de los LIG (Fig. 2).

En diciembre de 2018, el IELIG estaba completo para los dominios geológicos de la Cuenca del Guadalquivir y Cuencas Béticas Postorogénicas, Cuenca del Tajo-Mancha, Cuencas Levantinas, Cordillera Ibérica, Cordilleras Costero-Catalanas, Prebético y Cobertera Tabular de la Meseta, Campo de Gibraltar, Zona Cantábrica, Zona Asturoccidental-Leonesa, Zona Centroibérica, y Zona Sudportuguesa (las CCAA de Andalucía, Cataluña, País Vasco y Aragón han realizado los inventarios de sus territorios en los citados dominios geológicos). Están en ejecución en 2018 y 2019 los dominios geológicos de
Canarias, Cuenca del Duero-Almazán y Zona de Galicia Tras-os-Montes.

\subsection{Consideración del patrimonio de tipo paleontológico en la ficha técnica del IELIG}

Con respecto a los LIG de tipo paleontológico cabe destacar en la metodología del IELIG tanto su tratamiento, como varios aspectos técnicos.

1) Confidencialidad de la situación de los yacimientos propuestos como LIG. Este aspecto es crucial, puesto que el IELIG tiene el objetivo y el firme compromiso de garantizar la conservación del patrimonio geológico. De esta forma, ya en la ficha de selección de los LIG en la Fase 1, cuando son propuestos por los especialistas en paleontología, hay una casilla específica donde señalar la confidencialidad de la ubicación de los yacimientos paleontológicos. Así, es posible garantizar que las coordenadas y la ubicación nunca serán de acceso público, a menos que los yacimientos afectados se protejan física y legalmente. Esta información sólo estará disponible para las administraciones y organismos con competencias en la gestión y conservación en este patrimonio.

Inventario Español de Lugares de Interés Geológico
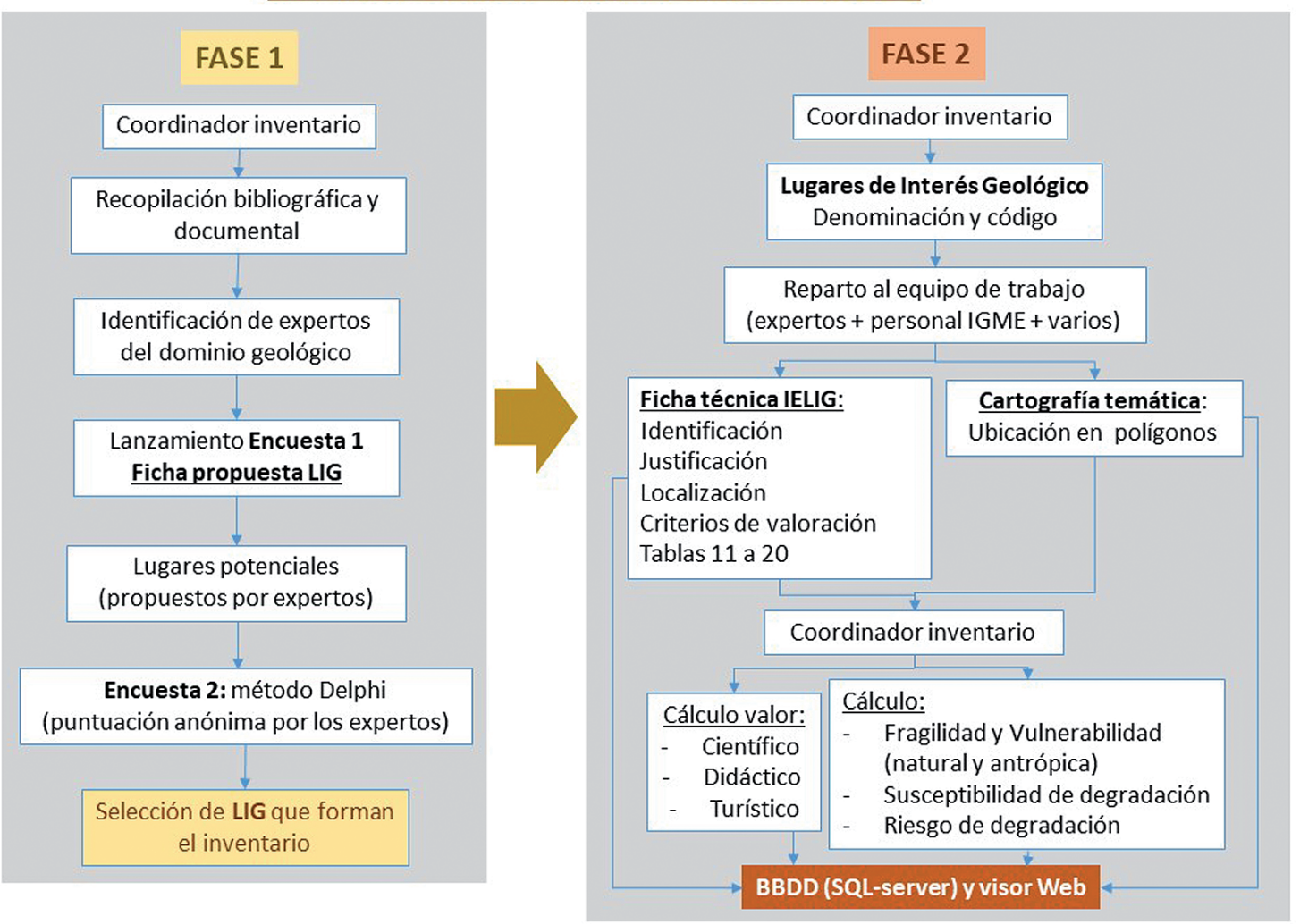

Figura 2. Esquema metodológico simplificado con las principales fases del Inventario Español de Lugares de Interés Geológico (IELIG). 
2) Caracterización en la Ficha técnica del IELIG. En las secciones 1 a 11 de esta ficha técnica se incluyen los datos que, tras el estudio comparativo de inventarios existentes, se han considerado relevantes para la identificación, uso y seguimiento de los LIG. Además, la ficha incluye los datos necesarios para realizar los cálculos del valor científico, didáctico y turístico, así como de su vulnerabilidad y riesgo de degradación. Las secciones 12 a 20 de la ficha (que se rellenarán, según proceda, de acuerdo con la naturaleza y el tipo de interés principal del LIG) recogen con detalle los contenidos relativos a los materiales y procesos de formación ígneos, metamórficos y sedimentarios, procesos de deformación o modelado, yacimientos mineralógicos o paleontológicos. De todas ellas, la sección número 20 es la que se contempla en exclusiva para los LIG de tipo paleontológico (Tabla 1) e incluye las características generales de los yacimientos, el contenido fosilífero (macrofauna, microfauna, macroflora y microflora), la composición de los fósiles del yacimiento y un apartado para incluir, si procede, las observaciones específicas del LIG.

Para el patrimonio de tipo paleontológico mueble, que es aquel que forma parte de colecciones o museos, se contempla dentro de la ficha técnica del IELIG la sección denominada "FICHA DESCRIPTIVA DEL MUSEO O COLECCIÓN", que, además de tratar sobre los fósiles, sirve también para documentar el resto del patrimonio geológico de tipo mueble (rocas, minerales y meteoritos). En estos casos, sería necesario cumplimentar las tablas 1 y 2 (Tabla 2) y la tabla número 4 (Tabla 3 ).

Tabla 1. Modificado de la sección número 20 de la ficha técnica del IELIG que hay que cumplimentar en la segunda fase del inventario para los LIG de interés principal de tipo paleontológico.

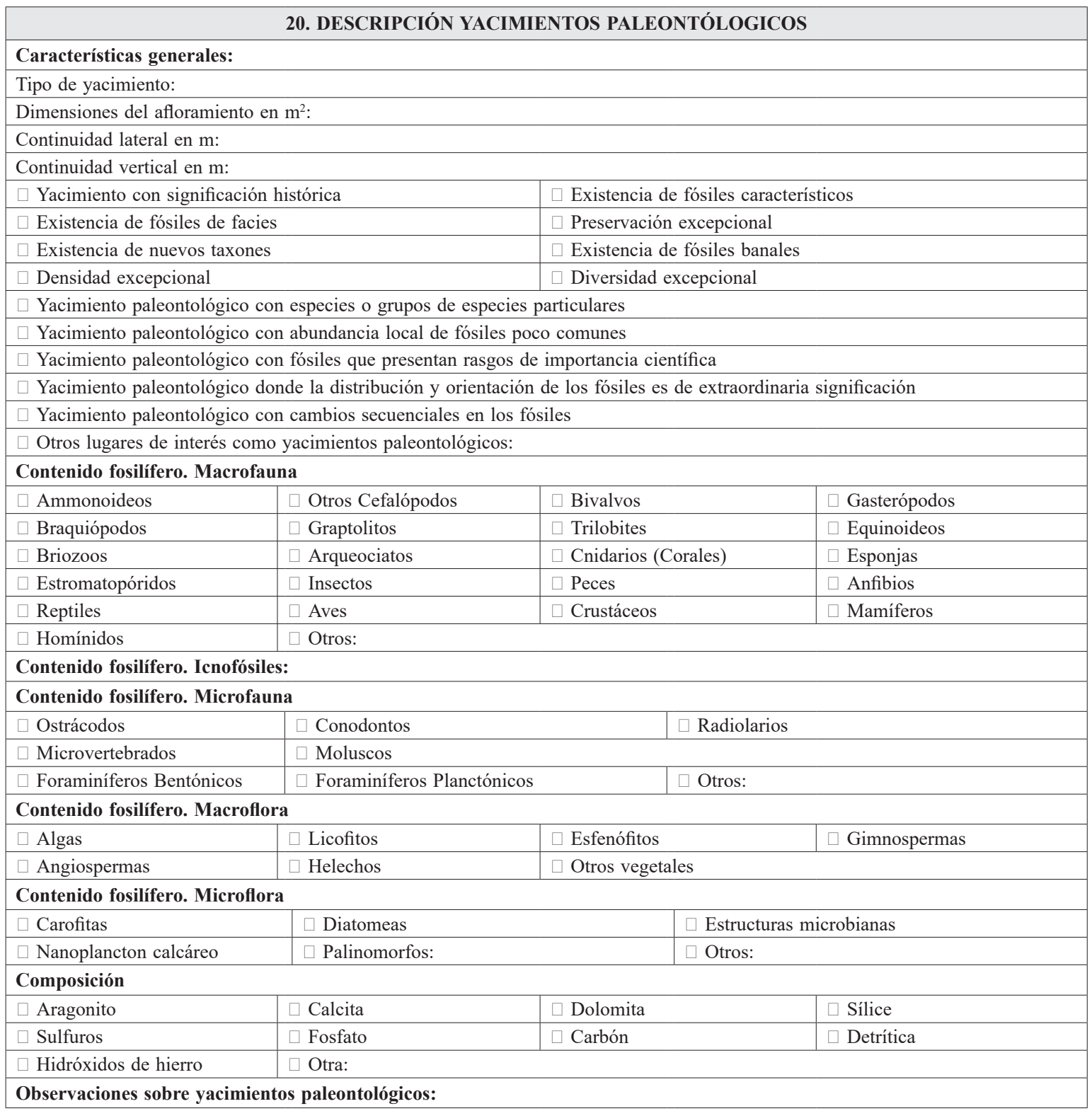


Tabla 2. Ficha descriptiva del museo o colección. Las categorías que contempla para el caso de los fósiles que sean patrimonio mueble son: Museo paleontológico: museo donde se exhiben, fundamentalmente, colecciones de fósiles. Centro de visitantes, Centro de interpretación o Aulas: centros en los que se expone material geológico o paleontológico ligado a un determinado espacio natural. Exo-museo: museo al aire libre acondicionado para la visita de materiales in situ. A menudo incluye también una sala donde se exponen colecciones de elementos extraídos del yacimiento. Museos temáticos: museos de diversa índole que desarrollan algún aspecto relacionado con la geología o la paleontología e incluyen colecciones de interés.

\begin{tabular}{|c|c|c|c|}
\hline \multicolumn{4}{|c|}{ 1. IDENTIFICACIÓN MUSEOS Y COLECCIONES } \\
\hline \multicolumn{4}{|l|}{ Código } \\
\hline \multicolumn{4}{|l|}{ Denominación } \\
\hline \multicolumn{4}{|l|}{ Tipo de Museo: } \\
\hline$\square$ Museo mineralógico & $\square$ Museo paleontológico & $\square$ Museo de la Ciencia & $\square$ Centro de visitantes/de interpretación \\
\hline$\square$ Exo-museo & $\square$ Museos temáticos & $\square$ Otros: & \\
\hline \multicolumn{4}{|l|}{ Breve descripción: } \\
\hline Acceso: & $\square$ Público & $\square$ Restringido & $\square$ No visitable \\
\hline \multicolumn{4}{|c|}{ 2. LOCALIZACIÓN MUSEOS Y COLECCIONES } \\
\hline UTM X : & UTM Y: & Huso: & Datum: \\
\hline \multicolumn{3}{|l|}{ Dirección: } & Código postal: \\
\hline \multicolumn{2}{|l|}{ Municipio: } & \multicolumn{2}{|l|}{ Isla (en su caso): } \\
\hline \multicolumn{2}{|l|}{ Provincia: } & \multicolumn{2}{|l|}{ Comunidad Autónoma: } \\
\hline \multicolumn{4}{|c|}{ Dominio geológico (GEODE): } \\
\hline \multicolumn{4}{|c|}{ Unidad Geotectónica de $2^{\circ}$ orden: } \\
\hline
\end{tabular}

Tabla 3. Modificado de la ficha descriptiva del museo o colección en la ficha técnica del IELIG. Tabla 4 donde se contemplan los fósiles que son parte del patrimonio geológico de tipo mueble.

\section{DESCRIPCIÓN MUSEOS Y COLECCIONES II}

\begin{tabular}{|c|c|c|c|c|}
\hline \multicolumn{5}{|c|}{ Interés para colecciones. Macrofauna } \\
\hline$\square$ ammonoideos & \multicolumn{2}{|c|}{$\square$ otros cefalópodos } & $\square$ bivalvos & $\square$ gasterópodos \\
\hline$\square$ braquiópodos & \multicolumn{2}{|l|}{$\square$ graptolitos } & $\square$ trilobites & $\square$ equinodermos \\
\hline$\square$ briozoos & \multicolumn{2}{|l|}{$\square$ arqueociatos } & $\square$ corales & $\square$ esponjas \\
\hline$\square$ estromatopóridos & \multicolumn{2}{|l|}{$\square$ insectos } & $\square$ peces & $\square$ anfibios \\
\hline$\square$ reptiles & \multicolumn{2}{|l|}{$\square$ aves } & $\square$ crustáceos & $\square$ mamíferos \\
\hline$\square$ homínidos & \multicolumn{4}{|l|}{$\square$ icnofósiles } \\
\hline \multicolumn{5}{|c|}{ Interés para colecciones. Microfauna } \\
\hline$\square$ ostrácodos & $\square$ conodontos & \multicolumn{3}{|l|}{$\square$ radiolarios } \\
\hline$\square$ foraminíferos bentónicos & \multicolumn{2}{|c|}{$\square$ foraminíferos planctónicos } & \multicolumn{2}{|l|}{$\square$ otros: } \\
\hline \multicolumn{5}{|c|}{ Interés para colecciones. Macroflora } \\
\hline$\square$ Algas & \multicolumn{2}{|l|}{$\square$ Licofitos } & $\square$ Esfenófitos & $\square$ Gimnospermas \\
\hline$\square$ Angiospermas & \multicolumn{2}{|l|}{$\square$ Helechos } & \multicolumn{2}{|l|}{$\square$ Otros vegetales } \\
\hline \multicolumn{5}{|c|}{ Interés para colecciones. Microflora } \\
\hline$\square$ carofitas & \multicolumn{2}{|l|}{$\square$ diatomeas } & \multicolumn{2}{|l|}{$\square$ estructuras microbianas } \\
\hline$\square$ nanoplancton calcáreo & \multicolumn{2}{|l|}{$\square$ palinomorfos: } & \multicolumn{2}{|l|}{$\square$ Otras: } \\
\hline \multicolumn{5}{|c|}{ Observaciones sobre los fósiles de interés para colecciones } \\
\hline \multicolumn{5}{|c|}{ Estructuras orgánicas de interés para colecciones } \\
\hline$\square$ bioturbación & \multicolumn{2}{|l|}{$\square$ estromatolitos } & $\square$ bioerosión & $\square$ Otras: \\
\hline \multicolumn{5}{|c|}{ Observaciones sobre las estructuras orgánicas de interés para colecciones: } \\
\hline \multicolumn{5}{|c|}{ Estructuras sedimentarias de interés para colecciones } \\
\hline$\square$ bounce marks & \multicolumn{2}{|l|}{$\square$ brush cast } & $\square$ crescent marks & $\square$ groove cast \\
\hline$\square$ prod marks & \multicolumn{2}{|l|}{$\square$ roll cast } & $\square$ flute cast & $\square$ ripples \\
\hline$\square$ herring bone & \multicolumn{2}{|c|}{$\square$ estratificación cruzada } & $\square$ estratificación flaser & $\square$ estratificación lenticular \\
\hline$\square$ laminación paralela & \multicolumn{2}{|c|}{$\square$ laminación convolute } & $\square$ laminación gradada & $\square$ laminación ondulada \\
\hline$\square$ concreciones & \multicolumn{2}{|l|}{$\square$ nódulos } & $\square$ grietas de desecación & $\square$ gotas de lluvia \\
\hline$\square$ huellas de carga & \multicolumn{2}{|l|}{$\square$ estilolitos } & \multicolumn{2}{|l|}{$\square$ Otras: } \\
\hline Otros elementos perteneci & ates al museo: & & & \\
\hline Ejemplares más destacado & & & & \\
\hline Observaciones en relación & n la exposición & as coleccio & & \\
\hline
\end{tabular}




\section{LIG DE INTERÉS PALEONTOLÓGICO MÁS SIGNIFICATIVOS EN EL IELIG}

El análisis del conjunto de los LIG inventariados hasta la fecha (el IELIG sigue en realización) y cuyo interés principal es el paleontológico, puede llevarse a cabo desde diferentes puntos de vista, pero existen, al menos, dos que se han considerado esenciales: a) el grupo fósil representado (vertebrados, invertebrados y flora) y b) el entorno geográfico. En el primer caso se han determinado las categorías de los fósiles representados en cada LIG para poder diferenciar los grupos propuestos y analizar su representatividad dentro del total del conjunto del IELIG. Además, en algunos de los LIG, dos o más de estos grupos aparecen representados en el mismo yacimiento, en cuyo caso se ha valorado la suma. El resultado es que el número de LIG que están integrados por yacimientos de vertebrados (111) e invertebrados (107) es bastante parecido y después, con una gran diferencia, están los LIG formados por flora (17) y el grupo restante de LIG (11) está integrado por cualquiera de dos de los grupos taxonómicos o por los tres (Fig. 3).

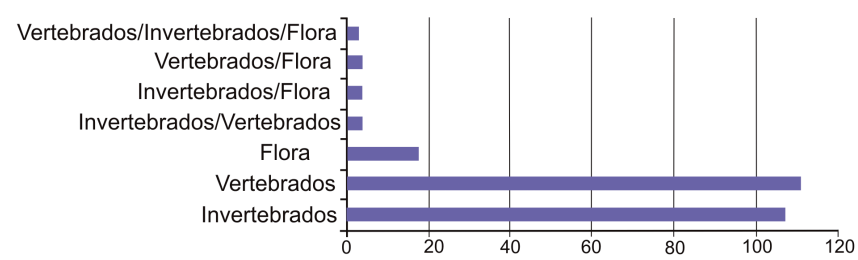

Figura. 3. Número de LIG de interés paleontológico constituidos por fósiles de vertebrados, invertebrados y flora que están incluidos en el IELIG a fecha de diciembre de 2018 .

Con respecto a las CCAA donde se ubican los diferentes LIG, en Andalucía es donde se concentra el mayor número de LIG paleontológicos (45), seguida por Castilla-La Mancha (40) (Fig. 4).

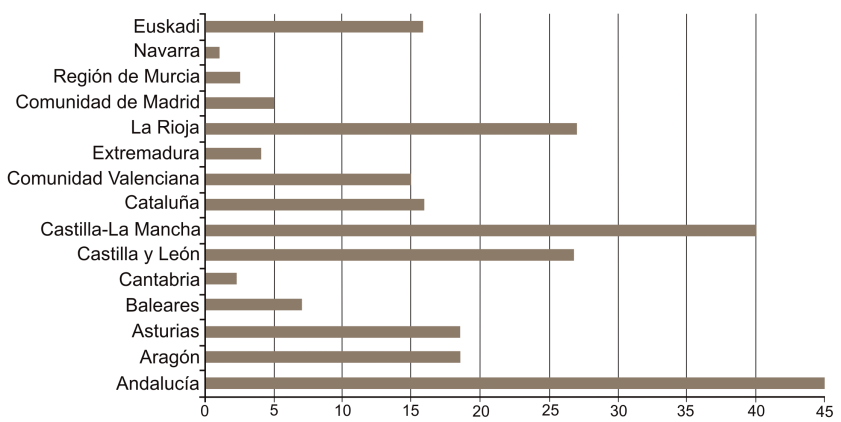

Figura 4. Número de los LIG de interés paleontológico que están incluidos en el IELIG, a fecha de diciembre de 2018, representados por cada Comunidad Autónoma. Andalucía, Castilla-La Mancha y La Rioja son las que tienen mayor número de LIG paleontológicos.
En el caso de Andalucía, la mayoría de los LIG están representados por yacimientos de invertebrados (25) mientras que los LIG representados por yacimientos de vertebrados (12) y flora (8) se encuentran en menor número (Fig. 5a). En la Figura 5b-d se puede observar la distribución de los diferentes LIG definidos por los grupos fósiles establecidos para las provincias andaluzas. Así, se observa que Huelva y Córdoba son las provincias donde hay mayor número de yacimientos de invertebrados declarados como LIG, mientras que Granada tiene el mayor número de yacimientos de vertebrados declarados. Se distingue también que los LIG de invertebrados aparecen representados en un mayor número de provincias que los LIG de vertebrados y flora, que sólo han sido descritos en tres provincias. Un dato curioso es que en la provincia de Cádiz no existe ningún LIG declarado.

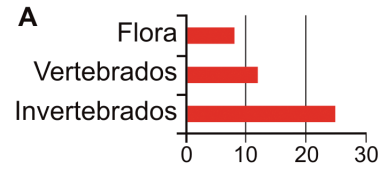

B

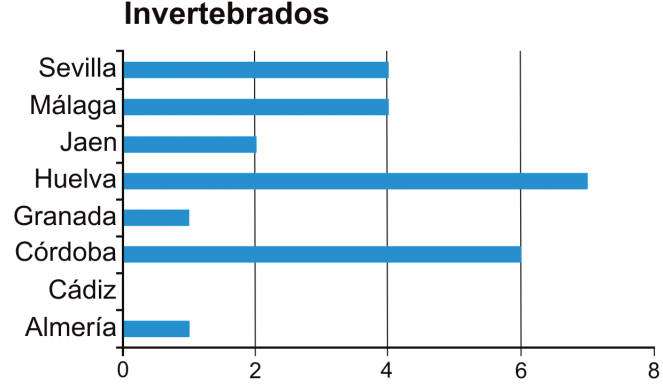

C Vertebrados

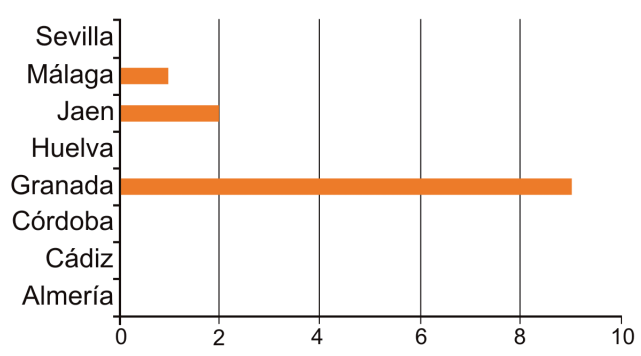

D Flora

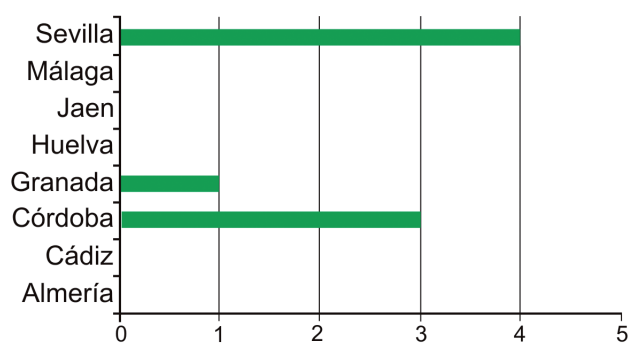

Figura 5. a) Número de LIG de interés paleontológico del IELIG incluidos dentro de la Comunidad Autónoma de Andalucía. Porcentaje de LIG constituidos por invertebrados b), vertebrados c) y flora d) por provincias en Andalucía. 
El caso de Castilla-La Mancha, la mayoría de los LIG inventariados corresponde con yacimientos fósiles de invertebrados (23), después de vertebrados (14) y flora (1). En La Rioja, hay declarados 27 LIG (Fig. 6), todos referidos a yacimientos de icnitas de dinosaurios. En Castilla y León, teniendo en cuenta que el inventario no ha concluido (se está inventariando actualmente la Cuenca del Duero-Almazán), el número de LIG constituidos por yacimientos de vertebrados (20) ocupa el segundo lugar dentro del conjunto de las CCAA (Fig. 6).

En Castilla y León, el registro que está inventariado hasta la fecha es más variado e incluye, además de los yacimientos de icnitas de dinosaurio localizados en las provincias de Burgos y Soria, los yacimientos de mamíferos del Pleistoceno de Torralba y de Ambrona (Soria), los yacimientos de vertebrados de Valles de Fuentidueña y Villacastín (Segovia), los yacimientos de homínidos del Cuaternario de la Sierra de Atapuerca y los de proboscídeos del Monte de la Abadesa (estos dos últimos en Burgos).

A nivel nacional, de los 245 LIG con interés paleontológico principal que hay en el IELIG, sólo 45 tienen alguna figura de protección declarada, ya sea a través de las leyes nacionales o autonómicas de patrimonio histórico o de las de patrimonio natural. Estos LIG protegidos pertenecen a las Comunidades de Aragón (7), Asturias (4), Cantabria (1), Castilla y León (8), Castilla La Mancha (3), Comunidad de Madrid (1), Comunidad Valenciana (3) y La Rioja (18).

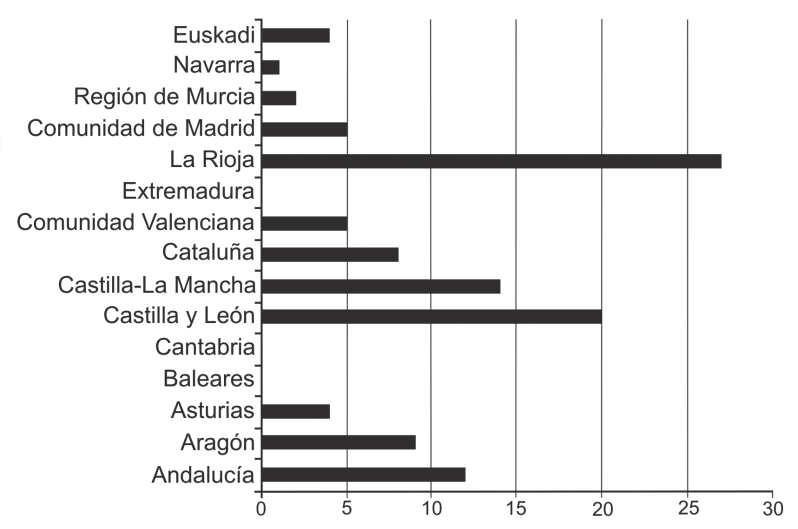

Figura 6. Número de LIG constituidos por yacimientos de vertebrados y su distribución por Comunidades Autónomas dentro del IELIG para diciembre de 2018.

\subsection{Algunos ejemplos de LIG paleontológicos en el IELIG y sus problemáticas}

Como ya han puesto de manifiesto Salazar et al. (2017), cuando se trata de yacimientos paleontológicos cuyo valor científico es muy elevado, y a pesar de que en la actualidad pueden estar totalmente desaparecidos por causas antrópicas, es necesario reconocer su ubicación real en el campo como LIG y merecen su consideración en el IELIG para asegurar que, al menos, se preserve la localidad de estos yacimientos. Antes de pasar a exponer algunos posibles problemas de conservación del patrimonio de tipo paleontológico, tanto si presentan una figura de protección legal como si no, se muestra el caso singular de un material paleontológico extraído en el pasado y que procedente de un LIG que a día de hoy presenta un elevado riesgo de desaparición. Es el yacimiento burgalés antes citado del Monte de la Abadesa. Se trata de un yacimiento histórico, cuyos fósiles aparecieron durante los trabajos realizados en una cantera para la extracción de arena situada en el paraje denominado "Monte de la Abadesa", a unos 4 kilómetros al sur de la cuidad de Burgos. El material extraído fue estudiado por Badillo (1952) y gran parte del mismo se encuentra depositado en el Museo Geominero (IGME) (Menéndez \& Rábano, 2015; Baeza \& Menéndez, 2016). En este caso, es importante destacar que la conciencia patrimonial de las personas implicadas en el descubrimiento, y la conservación en primera instancia y posteriormente de los ejemplares fósiles en cuestión (Íbero, 1955; IGME, 1955), ha hecho que el material paleontológico se haya conservado adecuadamente y siga hoy en día en una institución pública apropiada. Esto se debe a que fue el propio Padre José María Íbero quién depositó el material de parte del contratista de la cantera, D. Ataulfo Fidalgo, quién había contactado con el personal del IGME (con Luis Badillo y el ayudante técnico del museo José de la Revilla), y consideró que los restos encontrados no debían ser guardados en un Museo Arqueológico (en este caso hubiese sido el Museo Arqueológico Burgalés de la Casa Miranda) sino en un Museo Paleontológico, como él mismo expuso textualmente "como las arenas que contenían los mastodontes son Pontienses y muy anteriores a la aparición del hombre en la tierra, el museo propio para custodiarlos no es el arqueológico burgalés de la Casa Miranda, sino un museo paleontológico" (Íbero, 1955; pag. 6). El material del Monte de la Abadesa depositado en centros públicos es escaso, y no se tiene constancia de a donde fue a parar el resto del material estudiado por Badillo (1952) y que no está integrado en las colecciones del Museo Geominero. No fue hasta que se realizó la cartografía de la hoja geológica E 1:50.000 n 238 "Villagonzalo-Pedernales" cuando este yacimiento fue inventariado y catalogado como "Punto de Interés Geológico", y así aparece en la memoria anexa de 1992. Se cita en la memoria, además, el valor histórico de este yacimiento, pero se especifica que no se ha encontrado ningún resto fósil durante el reconocimiento de la zona durante los trabajos de campo. Hoy en día este paraje ha quedado prácticamente englobado dentro del área de influencia del término municipal de Burgos, de manera que se encuentra en un polígono industrial (Polígono Industrial Monte de la Abadesa), en el Sector S-22, espacio declarado 
como Suelo Urbanizable Industrial (S.U.R.) según consta en el Catálogo Arqueológico para el PGOU (Plan General de Ordenación Urbana) de Burgos. Como LIG no posee ninguna figura de protección.

Otro ejemplo, este más desafortunado, en lo referente a la destrucción o pérdida de un LIG, se registra en Castilla y León. Esta vez atañe al yacimiento de la sucesión del Ordovícico y Silúrico en Salas de la Ribera, constituido por fósiles de invertebrados, principalmente sinrabdosomas de graptolitos (supercolonias radiales) conservados excepcionalmente (Gutiérrez-Marco \& Lenz, 1998; Gutiérrez-Marco et al., 2008). Este LIG tiene, además, un valor histórico ya que en esta sección se encuentra el famoso yacimiento paleontológico del Silúrico de Salas de la Ribera, descubierto en el siglo XIX por Casiano de Prado. El yacimiento se encuentra entre los kilómetros 27 y 25 sobre el talud de la carretera N-536, que une Salas de la Ribera con el embalse de Peñarrubia. Se trata de un yacimiento incluido en el IELIG, que originalmente estaba recogido en el Inventario Nacional de PIG en el año 1983, y como Geosite de relevancia internacional en el Proyecto Global Geosites (García-Cortés, 2009). Este LIG se encuentra dentro de la Red Natura 2000 en el LIC (Lugar de Importancia Comunitaria) ES4130117 "Montes Aquilanos y Sierra de Teleno". Sin embargo, las obras acometidas en el verano de 2015 para la ampliación de la carretera N-536 por parte del Ministerio de Fomento produjeron daños irreparables en el yacimiento y los fósiles que contiene, ya que el nuevo talud ha sido recubierto por malla metálica y otros materiales que impiden el acceso directo a las diferentes capas. Esta acción fue objeto de denuncia en su momento, pero esta denuncia no posibilita la recuperación de este importante contexto geológico. Además, se da la circunstancia de que, después este yacimiento había sufrido estos desperfectos, una espectacular muestra de graptolitos, procedente del mismo se expuso en el Museo del Prado ( 17 de abril al 5 de agosto de 2018) como pieza integrante de la exposición temporal denominada "In lapide depictum" Pintura italiana sobre piedra 1530-1555; la cual reunió una selección de obras realizadas sobre piedra monocroma (pizarra y mármol blanco) por autores italianos, como Sebastiano del Piombo, Tiziano, Daniele da Volterra y Leandro Bassano.

El problema del expolio indiscriminado sigue siendo una realidad actual, por ello citamos un ejemplo reciente de un yacimiento paleontológico reconocido como LIG que ha sido expoliado, y de cuya repercusión se ha hecho eco la prensa digital. Este es el LIG (IB035) denominado "Fósiles de invertebrados marinos de los materiales del Jurásico Medio y Superior de los alrededores de Frías de Albarracín" (Teruel), que se ha categorizado con un interés excepcional respecto a su densidad de fósiles y diversidad taxonómica. En su ficha descriptiva se menciona la existencia de algunos leves deterioros, sin embargo, hasta la fecha no cuenta con ninguna figura legal de protección.

En Aragón, los agentes del Seprona (Guardia Civil) y de Seguridad Ciudadana reciben cursos de formación sobre patrimonio paleontológico, impartidos por personal cualificado de la Fundación Dinópolis. A pesar de la sensibilización existente sobre la protección del patrimonio paleontológico en Aragón, desgraciadamente siempre se producen expolios indiscriminados, la mayoría con fines lucrativos. En esta ocasión, los agentes del Seprona denunciaron, en agosto de 2014, a una persona que había sido sorprendida con gran cantidad de fósiles en su poder y muestreando con piquetas y cinceles. La denuncia fue realizada por infringir la Ley 3/1999 de Patrimonio Cultural Aragonés, y el material decomisado fue puesto a disposición del Servicio Provincial de Educación, Universidad, Cultura y Deporte. Aragón Digital (Fig. 7a), y las ediciones digitales de El Periódico de Aragón y el Heraldo de Aragón publicaron la noticia, y aprovecharon la coyuntura para recordar la prohibición por ley de recoger fósiles y la obligación de comunicar el hallazgo de los mismos, aunque no tengan trascendencia científica.
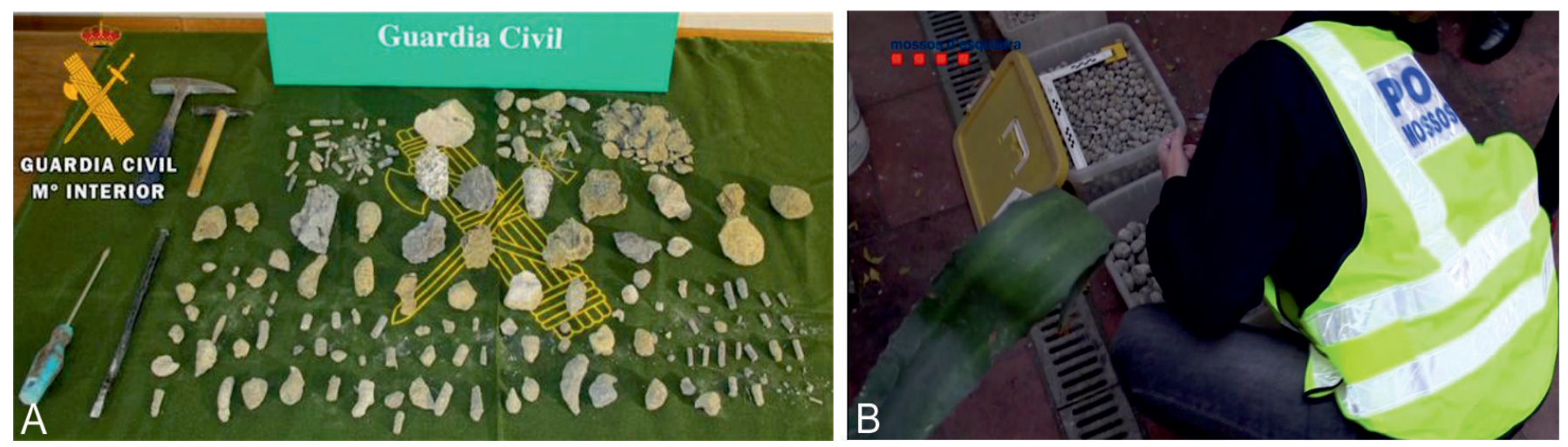

Figura 7. a) Fósiles incautados en Frías de Albarracín (Teruel). Tomado de Aragón Digital (22/8/2014). b) Un mosso d`Esquadra decomisando fósiles en Cataluña. Tomado de La Vanguardia digital (10/01/2018). 
Existen algunos LIG del IELIG que se corresponden, a su vez, con lugares de interés patrimonial definidos en inventarios autonómicos, los cuales reciben diferentes nombres y dependen de distintos organismos. En este contexto, podemos señalar algunos, como el "inventario andaluz de Georrecursos" (2011) que depende de la Consejería de Medioambiente y Ordenación del Territorio, de la Junta de Andalucía, o el "catálogo de lugares de interés geológico de Aragón" (2015) dependiente del Gobierno de Aragón. Un ejemplo importante es el del País Vasco, donde desde 1990 el Departamento de Medioambiente, Planificación Territorial y Vivienda del Gobierno Vasco está realizando numerosos inventarios de puntos de interés geológico en distintos ámbitos: Bizkaia (1990), Gipuzkoa (1991), Reserva de la Biosfera Geoparque Mundial UNESCO de Urdaibai (2005, 2010), y lugares de interés geológico del Geoparque de la Costa Vasca (2014).

Nos detenemos en el caso de la comunidad de Cataluña, cuyo departamento de territorio y sostenibilidad de la Generalitat ha desarrollado el "inventario de espacios de interés geológico" (EIG). Pero, además, el Instituto de Estadística de la Generalitat nos ofrece un listado de bienes culturales de interés nacional categorizado por tipos y comarcas que se puede consultar por años desde 1999. Viene al caso citarlos porque, ya sean lugares inventariados como LIG o con otras figuras de protección, los yacimientos paleontológicos allí son objeto de expolio indiscriminado. Así sucedió durante años en varios yacimientos paleontológicos catalanes como Pallars Jussà y Alt Urgell (Lérida), y la Selva (Girona) catalogados como "Bien Cultural de Interés Nacional" bajo la figura de Zona Paleontológica (ley autonómica catalana de 1993). En 2018 los Mossos d’Esquadra (Fig. 7b) intervinieron 20.000 piezas de posible interés científico en domicilios particulares (La Vanguardia, enero 2018) procedentes de 168 yacimientos arqueológicos y 32 paleontológicos, que habían sido expoliados y se habían reunido con fines puramente lucrativos, ya que existía la intención de subastarlas en internet. De esta forma, se ha puesto fin a una investigación del delito que había comenzado en 2016.

\subsection{Relación de los LIG de interés paleontológico con el patrimonio geológico mueble}

Los LIG paleontológicos brindan una oportunidad para poder desarrollar infraestructuras que alberguen patrimonio mueble y que permitan conocer la geología general de estos LIG y acercar la paleontología al público general: centros de interpretación, yacimientos musealizados, etc. Existen numerosos ejemplos en todo el territorio español; a continuación, vamos a citar algunos de ellos, ordenados por tiempo geológico.

\subsubsection{Yacimiento paleontológico del Ordovícico del túnel del Fabar (Ribadesella)}

Este caso es un LIG (ZCs052) "desaparecido", ya que el yacimiento como tal hoy día no se conserva, pues todo el contexto geológico se perdió durante la obra del Túnel Ordovícico del Fabar, en el tramo Caravia-Llovio (Ribadesella) de la Autovía del Cantábrico (A-8). En este caso, la declaración como LIG del lugar original propició la creación de una infraestructura que albergara el patrimonio mueble extraído y recuperado durante las obras, y viceversa, es decir, que la recuperación de este patrimonio favoreció la declaración de este afloramiento como LIG. Además, esta localidad cuenta también con la figura de "espacio geológico de interés internacional" acordado por la Subcomisión de Estratigrafía del Ordovícico (ISOSICS), perteneciente a la Unión Internacional de Ciencias Geológicas de UNESCO.

Las obras de la autovía en este tramo dieron comienzo a finales de 1998, concluyéndose unos 4 años después, en noviembre de 2002. Durante las obras del túnel, y al mismo ritmo que imponía la obra civil, los expertos en geología y paleontología implicados en la excavación, levantaron la columna estratigráfica en campo de una sucesión de 660 metros recuperando a la vez el material paleontológico correspondiente. El estudio, gestión y tratamiento de todo este material fructificó en numerosas publicaciones científicas y divulgativas, y en la creación de una exposición temporal denominada "Un Tesoro Geológico en la Autovía del Cantábrico. El Túnel Ordovícico de Ribadesella" (Gutiérrez-Marco \& Bernárdez, 2003). La exposición (Fig. 8a) se inauguró en 2003 en el Museo del Carmen en Ribadesella y estuvo expuesta prácticamente un año. Con posterioridad, fue instalada en diversos centros públicos, hasta que finalmente en el año 2007 quedó alojada de forma permanente en el centro que la vio nacer, el denominado Museo del Territorio de Ribadesella. La instalación definitiva en este centro público del citado patrimonio mueble, cuya financiación depende de la administración local, debe contribuir a la mejora de las instalaciones del centro, y así se espera que sea, ya que en diversas ocasiones desde el año 2007 ha estado cerrado temporalmente por falta de presupuesto.

\subsubsection{Yacimientos de icnitas de dinosaurio del Jurásico en Asturias}

La costa centro oriental asturiana conserva un elevado número de yacimientos de icnitas de dinosaurio registrados en los concejos de Colunga, Gijón, Ribadesella y Villaviciosa (García-Ramos et al., 2006). El extraordinario valor patrimonial de estos yacimientos paleontológicos, así como su excepcional interés científico, hizo que fuera reconocido y protegido mediante la declaración de Monumento Natural en el año 2001 (Boletín Oficial 
del Principado de Asturias, número 106 del 9 de mayo de 2001) y Lugar de Importancia Comunitaria dentro de la Red Natura 2000 (Diario Oficial de la Unión Europea, de diciembre de 2004). La figura de protección de "Monumento Natural" menciona expresamente la consideración de la geología y de los yacimientos paleontológicos, entre otros elementos naturales. Son varios los LIG que abarcan esta área geográfica de acuerdo con el IELIG: los acantilados mesozoicos de Tazones (15002), la sección del Jurásico de Lastres (15003), el yacimiento paleontológico de playa de Vega (31003), las icnitas de dinosaurio y acantilados de la ensenada de España (ZCs027) y la sección del Jurásico en la playa de la Ñora (ZCs043). Todos ellos están ligados al Museo del Jurásico de Asturias (MUJA) (Fig. 8b), que se inauguró en el año 2004 en la rasa de San Telmo del Concejo de Colunga y acoge una de las muestras más completas y didácticas del Jurásico asturiano. En él se recogen fósiles originales, réplicas y reconstrucciones de dinosaurios de la zona, así como de su actividad (huellas), pero también otros vertebrados, invertebrados y plantas del Jurásico de Asturias están muy bien representados.
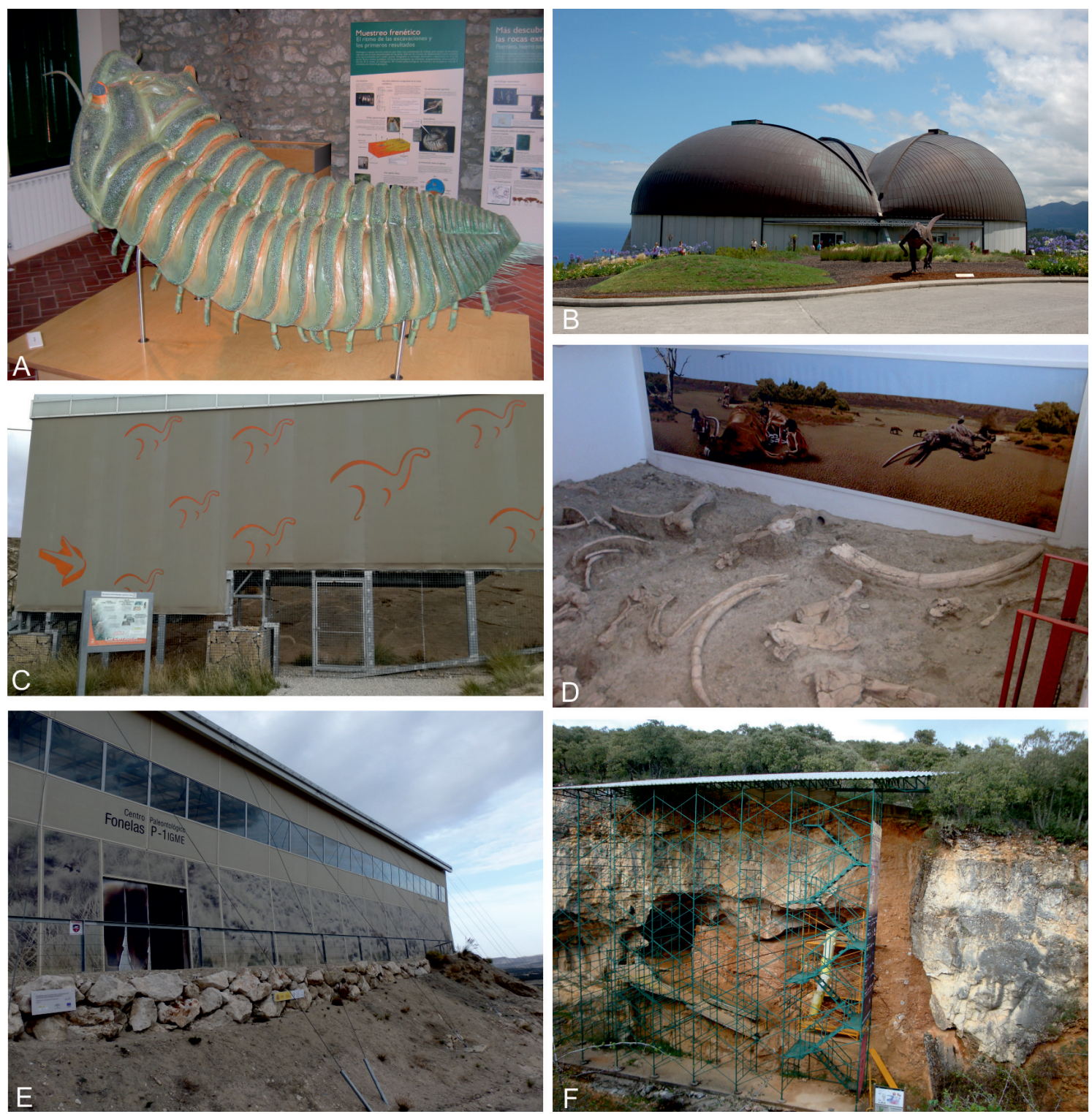

Figura 8. a) Reproducción de trilobites de la exposición "Un Tesoro Geológico en la Autovía del Cantábrico. El Túnel Ordovícico de Ribadesella", Museo del Carmen en Ribadesella (Asturias). b) Vista exterior del Museo del Jurásico de Asturias en la Rambla de San Telmo en Colunga (Asturias). c) Musealización in situ del yacimiento de icnitas de Las Cerradicas en Galve (Teruel). d) Vista parcial del yacimiento de vertebrados musealizado in situ en Ambrona (Soria). e) Vista exterior de la Estación Paleontológica "Valle del Río Fardes" en Fonelas (Granada); f) Vista exterior de uno de los yacimientos de homínidos del Cuaternario de la Sierra de Atapuerca (Burgos). 


\subsubsection{Yacimientos de dinosaurios del Jurásico- Cretácico en Galve (Teruel)}

Son otro magnífico ejemplo (Fig. 8c) de patrimonio paleontológico que tienen gran valor científico porque han proporcionado ejemplares a partir de los que se han descrito nuevos taxones de dinosaurios, como el Aragosaurus y Galvesaurus (Sanz et al., 1987; Barco et al., 2005, respectivamente). Estos yacimientos son muy fosilíferos, proporcionando un elevado número de ejemplares de vertebrados, invertebrados y flora. Fueron catalogados como LIG (IB207) en el año 2007, con interés principal paleontológico y están protegidos parcialmente con la figura de Bien de Interés Cultural, con categoría de Zona Paleontológica, desde el año 2003. La localidad de Galve, a su vez, está incluida en el Parque Cultural del Maestrazgo y desde los años noventa del siglo XX, cuenta con un museo privado conocido por toda la comunidad científica especializada en el tema. En la actualidad, una de las sedes de Dinópolis se enmarca en esta área geográfica, la denominada "Legendpark". Este centro de interpretación está dedicado a los dinosaurios de la zona, mostrando huesos fósiles y reproducciones de los animales y de un nido de huevos con crías de dinosaurios encontrados en la localidad.

\subsubsection{Yacimiento de vertebrados del Cretácico Inferior de Las Hoyas (Cuenca)}

Es uno de los ejemplos de conservación excepcional (Konservat-Lagerstätte) reconocido a nivel mundial. El yacimiento ha dado lugar a hallazgos singulares y nuevos taxones de muchos grupos de vertebrados, invertebrados y plantas (Poyato-Ariza \& Buscalioni, 2016). Está catalogado como LIG (IB216) en 2007 y está incluido en el Monumento Natural "Palancares y Tierra Muerta", declarado en 2001 por Castilla-La Mancha. Posteriormente, en el año 2016, fue declarado Bien de Interés Cultural con categoría de Zona Paleontológica. En la actualidad, además del Museo de Paleontología de Castilla-La Mancha en Cuenca, existen varios centros de interpretación ligados a la denominada "Ruta de los dinosaurios" que muestran fósiles de este LIG. Uno de los ellos, "Territorio Concavenator", está exclusivamente dedicado al yacimiento de Las Hoyas, y se ubica en la localidad de Cañada del Hoyo. Contiene una muestra importante de fósiles del yacimiento, así como réplicas y reconstrucciones del ecosistema cretácico.

\subsubsection{Yacimientos de moluscos del Plioceno marino de la provincia de Málaga}

La importancia y diversidad de estos yacimientos es indiscutible, de hecho, cuatro de ellos (El Padrón, Velerín, Burriana y Barranco de Maro) han sido declarados LIG (AND504, AND506, AND550, AND551, respectivamente) y aparecen recogidos en el Inventario Andaluz de
Georrecursos. Este hecho, muy probablemente, respaldó la creación del Museo Municipal Paleontológico de Estepona (MMPE) en Málaga, a finales del año 2000 (Vera Peláez, 2010-2011). Entre otras colecciones y recursos, el MMPE alberga una gran colección de referencia internacional de moluscos (gasterópodos, bivalvos, escafópodos y poliplacóforos) y otros invertebrados marinos de las cuencas pliocenas andaluzas, con especial relevancia los procedentes de la cuenca de Estepona. Presenta recreaciones paleoambientales que ponen de manifiesto cómo era la costa durante el Plioceno.

\subsubsection{Yacimiento arqueológico y paleontológico de mamiferos del Pleistoceno de Ambrona (Soria)}

En este caso la musealización del yacimiento in situ y el museo anexo tuvieron lugar muy incipientemente. Aunque el yacimiento era conocido desde finales del siglo XIX, los primeros trabajos paleontológicos en detalle no tuvieron lugar hasta 1960, y fue durante las excavaciones de 1963, a iniciativa de Emiliano Aguirre, cuando se realizaron las obras para musealizar el yacimiento (Fig. 8d), idea que fue bastante novedosa para la época. En 1973 se realizó la ampliación de lo que hoy se denomina "Museo y yacimiento arqueo-paleontológico de Ambrona" (ver Santonja et al., 2005). El conjunto está integrado, por dos áreas museísticas diferentes, cuyo propósito es hacer accesible y comprensible el yacimiento al público. Una de ellas se ubica en el contexto geológico real con la disposición original in situ de diferentes ejemplares fósiles, destacando numerosos fósiles de Elephas (Palaeoloxodon) antiquus, incluidas las defensas. La otra área, situada contiguamente, se trata del museo en sí mismo, donde las explicaciones pertinentes se ofrecen en diversos soportes expositivos e interpretativos, junto con fósiles de la fauna que habitó, además de numerosos vestigios de la industria lítica utilizada por los seres humanos que vivieron en este lugar. En este caso la importancia que posee el conjunto arqueo-paleontológico de los yacimientos de Ambrona y Torralba del Moral propició que fuera declarado Bien de Interés Cultural en 1995 en la categoría de Zona Arqueológica, pasando posteriormente a ser LIG (IB210) y formar parte del IELIG.

\subsubsection{Yacimiento de vertebrados del Pleistoceno de Fonelas (Granada)}

Debido a su importancia, al valor científico, educativo y divulgativo, el yacimiento P-1 fue declarado Geosite de relevancia internacional para España (Proyecto Global Geosites en García-Cortés et al., 2009) y forma parte de la Estrategia Andaluza de Geodiversidad de la Consejería de Medio Ambiente de la Junta de Andalucía, dentro del inventario de Georrecursos (AND303). En el caso de 
este yacimiento paleontológico, se ha creado la Estación Paleontológica "Valle del Río Fardes" (EPVRF) que es una infraestructura de campo, donde se integran actividades de "Investigación, Divulgación y Docencia" en torno al yacimiento de grandes mamíferos de inicios del Pleistoceno (Fig. 8e). El yacimiento fue descubierto en el año 2000 y posteriormente entre los años 2001 y 2009 fue objeto de numerosas campañas de prospección y excavación (Arribas et al., 2008, 2009). La investigación llevada a cabo sobre el yacimiento ha dado a conocer el contenido faunístico fósil, el modelo genético del yacimiento y su edad. La propiedad donde se halla el yacimiento (una finca de 25 hectáreas) fue adquirida por el IGME en 2010. En 2012 se reactivó la investigación dentro ya de dicho proyecto y al año siguiente, en 2013, se construyó el edificio que alberga la estación. En la actualidad cuenta con un programa de actividades y visitas programadas abiertas al público, con 3.273 visitantes en el año 2018.

\subsubsection{Yacimientos de homínidos del Cuaternario de Atapuerca (Burgos)}

Uno de los casos más emblemáticos son los yacimientos de la Sierra de Atapuerca (Arsuaga, 2006; Carbonell \& Tristán, 2017), que han dado lugar a un registro arqueológico y paleontológico (principalmente paleoantropológico) único en el mundo. Fueron declarados Sitio Arqueológico de Atapuerca $n^{\circ} 989$ (Junta de Castilla y León, 1991) y posteriormente declarados Patrimonio de la Humanidad en el año 2000. En el año 2007 fue declarado BIC e incluido en el IELIG como LIG con un interés principal de tipo paleontológico (IB209). Este espectacular entorno con tan importantes yacimientos ha sido un ejemplo de buena gestión del patrimonio paleontológico y arqueológico mueble e inmueble, combinando las visitas guiadas a los yacimientos de la Sierra de Atapuerca (Fig. 8f), que se iniciaron en 1998, y las visitas a centros expositivos, inaugurados a partir del año 2001. El Centro de Arqueología Experimental, en Atapuerca, expone todo lo relacionado con objetos arqueológicos y el Museo de la Evolución Humana, en Burgos, todo lo relacionado con la evolución humana y elementos paleontológicos. Actualmente, el Sistema Atapuerca, Cultura de la Evolución (SACE) es el órgano gestor dependiente de la Consejería de Cultura y Turismo de la Junta de Castilla y León, y el encargado de coordinar todos los aspectos divulgativos y científicos asociados a la arqueología y paleontología de estos yacimientos.

\section{CONCLUSIONES}

El patrimonio paleontológico es un tipo de interés contemplado dentro del Inventario Español de Lugares de
Interés Geológico (IELIG). Este inventario del patrimonio geológico a escala nacional es de tipo sistemático $\mathrm{y}$, por ello, tiene la obligación de ser representativo de la geodiversidad de España como indica la Ley 42/2007 y 33/2015 del patrimonio natural y la biodiversidad. Como tal, debe reunir Lugares de Interés Geológico (LIG) de todas las disciplinas de las Ciencias de la Tierra y, también, de las Ciencias de la Vida, para incluir el caso de la paleontología. Además, como el IELIG está recogido y reconocido por esta legislación de ámbito estatal, se está realizando con una metodología que ha sido corroborada por más de 50 especialistas de toda España y que está estandarizada para poder ofrecer resultados lo más objetivos, comparables y reproducibles posibles. La mayor ventaja de esta metodología es que permite la comparación entre LIG de muy diferente naturaleza y es una herramienta fundamental para la gestión del patrimonio geológico español. El IELIG se encuentra disponible en acceso libre en la página web del Instituto Geológico y Minero de España (http://info.igme.es/ielig/), siempre respetando la confidencialidad establecida por los autores que propusieron los LIG de tipo paleontológico para garantizar su conservación. El IELIG no entra en conflicto con la realización de otros inventarios temáticos de patrimonio paleontológico a escala regional y local que apliquen metodologías de valoración que sean más específicas y más extensas, pues éstos tienen objetivos diferentes a los contemplados en el IELIG.

Sin embargo, hasta la fecha, los LIG incluidos en este inventario nacional no tienen una categoría de protección por el mero hecho de encontrarse en dicho inventario, puesto que por sí mismos no son una figura específica de protección por ley. Algunos sí están protegidos por figuras de protección incluidas en la legislación nacional, autonómica y/o local. En el caso de los yacimientos paleontológicos, se observa que muchos de los que están incluidos en el IELIG están protegidos por alguna figura autonómica de protección del patrimonio histórico y cultural, como por ejemplo Bien de Interés Cultural o Zona Paleontológica. Sólo los LIG que han sido reconocidos legalmente en los inventarios autonómicos de patrimonio geológico de Andalucía, Cataluña, País Vasco y Aragón tienen una protección real. Este hecho no impide que algunos de los yacimientos paleontológicos más emblemáticos del patrimonio geológico de España hayan desaparecido por factores antrópicos (principalmente por obras públicas, minería, vandalismo, expolio, entre otros). Sin embargo, el reconocimiento y la protección de muchos LIG de tipo paleontológico está íntimamente ligada al desarrollo de museos y centros de interpretación (in situ y ex situ), y viceversa, lo cual pone de manifiesto una relación recíproca LIG-patrimonio mueble. 


\section{AGRADECIMIENTOS}

Este trabajo ha sido financiado por los proyectos de investigación IGME-2218 "Actuaciones para el desarrollo del Plan Estratégico del Patrimonio Natural y de la Biodiversidad 2011-2017 en relación con la geodiversidad y el patrimonio geológico", IGME-2457 "Mejora del conocimiento del patrimonio geológico de Castilla-La Mancha" y el proyecto CGL-2013-42643-P. Agradecemos a los dos revisores anónimos y a los editores de este monográfico (E. Fernández y E. Peñalver) todos los comentarios y sugerencias al manuscrito original.

\section{REFERENCIAS}

Águeda, J., Elízaga, E., González-Lastra, J.A., Palacio, J., Sánchez de la Torre, L., Suárez de Centi, C. \& Valenzuela, M. 1985. Puntos de Interés Geológico de Asturias. Volumen I. Ministerio de Industria y Energía. IGME, Madrid. $132 \mathrm{p}$.

Alcalá, L. \& Morales, J. 1991. The paleontological heritage of the Community of Madrid. Mém. Soc. Géol. Fr. Nouvelle Série, 165. 13-16. Paris.

Arana, R., Rodríguez-Estrella, T., Mancheño, M.A., Guillén, F., Ortiz, R., Fernández Tapia, T. \& Del Ramo, A. 1999. El Patrimonio Geológico de la Región de Murcia. Fundación Séneca, Murcia. 399 p.

Arribas, A., Garrido, G., Viseras, C., Soria, J.M., Solano, J.G., Hernández, R., Baeza, E., Durán, J.J., Laplana, C., Pla, S., Carrión, J.S., Carroza, J.A., Lorenzo, C., Lozano, R.P., Díez, J.C., Navazo, M., Terradillos, M., Alonso, R., Fernández, S., Gumiel, J.C., de Frutos, C., Garcés, M. \& López, J. 2008. Investigación paleontológica y estratigráfica de la Formación Guadix entre los años 2001 y 2007: Fonelas P-1 y el Proyecto Fonelas. In: Vertebrados del Plioceno Superior Terminal en el Suroeste de Europa: Fonelas P-1 y el Proyecto Fonelas (ed. Arribas, A.). Cuadernos del Museo Geominero, 10, 21-54.

Arribas, A., Garrido, G., Viseras, C., Soria, J.M., Pla, S., Solano, J.G., Garcés, M., Beamud, E. \& Carrión, J.S. 2009. A mammalian lost world in southwest Europe during the late Pliocene. PLoS ONE, 4, e7127; doi: 10.1371/journal. pone. 0007127.

Arsuaga, J.L. 2006. Atapuerca, Patrimonio de la Humanidad: 30 Años de Excavaciones y Descubrimientos. Junta de Castilla y León, 320 pp.

Badillo, L. 1952. Nota sobre un nuevo yacimiento de "Mastodon longirostris", Kaup. Notas y Comunicaciones del Instituto Geológico y Minero de España, 28, 89-94.

Baeza, E. \& Menéndez, S. 2016. La colección de proboscídeos fósiles del "Monte de la Abadesa" (Burgos) del Museo Geominero (IGME, Madrid): tratamientos de conservación. Cuadernos del Museo Geominero, 20, 101-106.

Barco, J.L., Canudo, J.I., Cuenca-Bescós, G. \& Ruiz-Omeñaca, J.I. 2005. Un nuevo dinosaurio saurópodo Galvesaurus herreroi gen. nov., sp. nov., del tránsito Jurásico-Cretácico en Galve (Teruel, NE de España). Naturaleza Aragonesa, 15, 4-17.

Carbonell, E. \& Tristán, R.M. 2017. Atapuerca. 40 Años Inmersos en el Pasado. Editorial National Geographic, $400 \mathrm{pp}$.

Carcavilla Urquí, L., López Martínez, J. \& Durán Valsero, J.J. 2007. Patrimonio geológico y geodiversidad: investigación, conservación, gestión y relación con los espacios naturales protegidos. Cuadernos del Museo Geominero, 7, 360 pp.

Castillo, C., Castillo, J., Coello, J.J., Martín, E., Martín, M. \& Méndez, A. 1999. La tutela del patrimonio paleontológico en Canarias. Valoración general. Coloquios de Paleontología, 50, 9-21.

Delvene, G., Jiménez, R., Vegas, J., Rábano, I. \& Menéndez, S. 2016. Del campo a la vitrina: análisis de las casuísticas entre individuos-finalidad-ubicación en relación con el patrimonio paleontológico mueble. Cuadernos del Museo Geominero, 20, 145-151.

Delvene, G., Vegas, J., Jiménez, R., Rábano, I. \& Menéndez, S. 2018. From the field to the museum: analysis of groups-purposes-locations in relation to Spain's moveable palaeontological heritage. Geoheritage, 10, 451-462; doi: 10.1007/s12371-018-0290-3.

Díaz-Martínez, E. 2011. Typology of heritage: Where does geoheritage fit in? Forum GeoReg, Villeneuve d'Ascq, France, 23-27 October 2011 - Programme and Abstracts, p.102. (http://www.igme.es/patrimonio/publicaciones/ CongReun.htm).

Díaz-Martínez, E. \& Fernández-Martínez, E. 2015. El valor del patrimonio geológico: 1, fundamentos y significado. In: Patrimonio Geológico y Geoparques, Avances de un Camino para Todos (eds. Hilario, A., Mendia, M., MongeGanuzas, M., Fernández, E., Vegas, J. \& Belmonte, A.). Cuadernos del Museo Geominero, 18, 13-18.

Díaz-Martínez, E., García-Cortés, A. \& Carcavilla, L. 2013. Los fósiles son elementos geológicos y el patrimonio paleontológico es un tipo de patrimonio natural. Cuadernos del Museo Geominero, 15, 583-589.

Díaz-Martínez, E., Vegas, J., Carcavilla, L. \& García-Cortes, A. 2016. Base conceptual, estado de la cuestión y perspectivas de la gestión y conservación del patrimonio paleontológico. Cuadernos del Museo Geominero, 20, 159-163.

Duque, L.C., Elízaga, E. \& Vidal Romaní, J.R. 1983. Puntos de Interés Geológico de Galicia. Instituto Geológico y Minero de España, Madrid. 103 p.

Elízaga, E. 1988. Georrecursos culturales. In: Geología Ambiental. ITGE. Madrid. pp. 85-100.

Elízaga, E., Abril, J., Duque, L.C., García Salinas, F. \& Murcia, V. 1980 Los puntos geológico-mineros de interés singular como patrimonio natural. Su inventario y metodología de estudio. I Reunión Nacional de Geología Ambiental y Ordenación del Territorio. Volumen de Comunicaciones, 21. Santander.

Elízaga, E., Gallego, E. \& García-Cortés, A. 1994. Inventaire National des sites d'Intérêt Géologique en Espagne: Méthodologie et Déroulement. Mémoire Societé Géologique France, 164, 103-110. 
Fernández López, S.R. 1998. Tafonomía y Fosilización. In: Tratado de Paleontología, Tomo 1 (ed. Meléndez, B.). Consejo Superior de Investigaciones Científicas, 51-107 pp.

García-Cortés, A., Águeda Villar, J., Palacio Suárez-Valgrande, J. \& Salvador González, C.I. (eds.). 2009. Spanish Geological Frameworks and Geosites: an Approach to Spanish Geological Heritage of International Relevance. Instituto Geológico y Minero de España. 234 pp.

García-Cortés, A., Carcavilla, L., Díaz-Martínez, E. \& Vegas, J. 2018. Documento Metodológico para la Elaboración del Inventario Español de Lugares de Interés Geológico (IELIG). Versión 5/12/2014, Actualización 12/07/2018. http://www.igme.es/patrimonio/descargas.htm. 65.

García-Ramos, J.C., Piñuela, L. \& Lires, J. 2006. Atlas del Jurásico de Asturias. Ediciones Nobel, S.A. Oviedo, 225 pp.

Gómez, E. \& Morales, J., 2000. Inventario y valoración. In: Patrimonio Paleontológico de la Comunidad de Madrid (eds. Morales, J., Nieto, M., Amezua, L., Fraile, S., Gómez, E., Herráez, E., Peláez-Campomanes, P., Salesa, M.J., Sánchez, I.M. \& Soria, D.). Serie de la Consejería de Educación, Comunidad de Madrid, 316-331.

Gutiérrez-Marco, J.C. \& Bernárdez, E. 2003. Un Tesoro Geológico en la Autovía del Cantábrico. El Túnel Ordovícico del Fabar en Ribadesella, Asturias. Ministerio de Fomento, Madrid, 398 pp.

Gutiérrez-Marco, J.C. \& Lenz, A. 1998. Graptolite synrhabdosomes: biological or taphonomical entities? Paleobiology, 24, 37-48; doi: 10.1017/S0094837300019953.

Gutiérrez-Marco, J.C., Rábano, I., Liñán, E., Gozalo, R., Fernández-Martínez, E., Arbizu, M., Méndez-Bedia, I., Pieren-Pidal, A. \& Sarmiento, G. 2008. Las sucesiones estratigráficas del Paleozoico Inferior y Medio. In: Contextos Geológicos Españoles. Una Aproximación al Patrimonio Geológico Español de Relevancia Internacional (ed. García-Cortés, A.). Instituto Geológico y Minero de España, Madrid, pp. 31-43.

Henriques, M.E. \& Pena dos Reis, R. 2015. Framing the Palaeontological Heritage within the Geological Heritage: An Integrative Vision. Geoheritage, 7, 249-259; doi: 10.1007/s12371-014-0141-9.

Íbero, J.M. 1955. Remembranzas geológicas y protohistóricas de Burgos y Oña: discurso leído en la Academia Burgense de Historia y Bellas Artes por José María Ibero. Publicaciones de la Institución Fernán González Academia Burgense de Historia y Bellas Artes, 1-16.

IGME, 1955. Memoria General. Instituto Geológico y Minero de España, Madrid, 107 pp.

Meléndez, G. \& Soria, M. 1994. The legal framework and scientific procedure for the protection of palaeontological sites in Spain: recovery of some special sites affected by human activity in Aragón (eastern Spain). In: Geological and Landscape Conservation (eds. O'Halloran, D., Green, C., Harley, M., Stanley, M. \& Knill, J.). Geological Society, London, 329-334.

Meléndez, G. \& Soria, M. 1999. Situación actual del patrimonio paleontológico en España. Boletín del Instituto Andaluz de Patrimonio Histórico (IAPH), 29, 128-141.

Meléndez, G. \& Soria LLop, C. 2000. El debate sobre el Patrimonio Paleontológico en España: el papel de la sociedad, las administraciones públicas y los paleontólogos. Geotemas, 1, 317-320.

Meléndez, G. \& Soria LLop, C. 2002. Presente y futuro del patrimonio paleontológico de Teruel: medias de protección, gestión y proyección social. In: El Patrimonio Paleontológico de Teruel (eds. Meléndez Hevia, G. \& Peñalver Mollá, E.), 429-443.

Menéndez, S. \& Rábano, I. 2015. Proboscídeos fósiles de la provincia de Burgos en las colecciones paleontológicas del Museo Geominero (Instituto Geológico y Minero de España, Madrid). Libro de resúmenes. XXI Bienal de la Real Sociedad Española de Historia Natural, Burgos, 79-80.

Mendía, M., Hilario, A., Apellaniz, E., Aranburu, A., Carracedo, M., Cearreta, A., Eguíluz, L., Gil Crespo, P.P., González, M.J., López-Horgue, M., Martínez-Torres, L.M. \& Mugerza, I. 2013. El inventario de lugares de interés geológico de la comunidad autónoma del País Vasco (CAPV). Cuadernos del Museo Geominero, 15, 457-466.

Morales, J. 1996. El patrimonio paleontológico. Bases para su definición, estado actual y perspectivas futuras. In: El Patrimonio Geológico. Bases para su Valoración, Protección, Conservación y Utilización (ed. Cendrero, A.). Ministerio de Obras Públicas, Transportes y Medio Ambiente, Madrid, 39-51.

Morales Romero, J., Azanza Asensio, B. \& Gómez Ruiz, E. 1999. El Patrimonio Paleontológico Español. Coloquios de Paleontología, 50, 53-62.

Poyato-Ariza, F.J. \& Buscalioni, A.D. (eds.) 2016. Las Hoyas: A Cretaceous Wetland. Verlag Dr. Friedrich Pfeil, 262 pp.

Romero, G. 2005. La protección del patrimonio paleontológico en la región de Murcia: experiencias e iniciativas. De Re Metallica, 5, 21-30.

Salazar, A., Carcavilla, L., Díaz-Martínez, E., García-Cortés, Á. \& Vegas, J. 2017. Yacimientos paleontológicos desaparecidos ¿por qué inventariarlos? Cuadernos del Museo Geominero, 21, 33-38.

Santonja, M., Pérez-González, A. \& Mora, R. 2005. Investigaciones recientes (1990-1997) en los yacimientos de Ambrona y Torralba (Soria, España). In: Los Yacimientos Paleolíticos de Torralba y Ambrona (Soria). Un Siglo de Investigaciones Arqueológicas, 5, 15-17.

Sanz, J.L., Buscalioni, A.D., Casanovas, M.L. \& Santafé, J.V. 1987. Dinosaurios del Cretácico Inferior de Galve (Teruel, España). Estudios Geológicos, Volumen extraordinario, Galve-Tremp, 45-64.

Tamés, P., Mendiola, I. \& Pérez, C. (Coords.) 1991. Puntos de Interés Geológico de Guipúzcoa. Diputación Foral de Guipúzcoa, San Sebastián. 167 pp.

Vegas, J., Delvene, G., Jiménez, R., Rábano, I. \& Menéndez, S. 2017. Análisis de la Situación en España y Propuestas para Promover Mecanismos para Regular la Recolección y Controlar el Comercio de Elementos Muebles del Patrimonio Geológico. Instituto Geológico y Minero de España. Informe inédito entregado al MAPAMA. 57 pp.

Vera Peláez, J.L. 2010-2011. El Museo Municipal Paleontológico de Estepona, diez años de investigación, exposición y difusión de la paleontología. Nautilus, 6, 83-89. 
